UNDERGROUND MINING ENGINEERING 35 (2019) 37-48 $\quad$ UDK 62

\title{
APPLICATION OF JKSIMBLAST SOFTWARE IN DRIFTING OPERATIONS
}

\author{
Luka Crnogorac ${ }^{1}$, Rade Tokalić $\mathbf{1}$, Suzana Lutovac ${ }^{1}$, Miloš Gligorić ${ }^{1}$, Aleksandar \\ Ganić $^{1}$
}

\begin{abstract}
This paper presents a review of the advantages of application of JKSimBlast 2DFace software in design phase of underground premises. The aim of this research was to show possibilities of the software and possibility of its application in design of underground premises with suggestions for further work. A model of a drift "TIP 5" was developed and analysed in the software to show all the possibilities of the application of software in underground construction.

Further work would require a detailed field work to gather input data required for more detail analysis of the effects of blasting in the software itself, as well as validation of the results given by software on the field.
\end{abstract}

Keywords: software; underground construction; drilling; blasting; drifting;

\section{INTRODUCTION}

In mining, as in all other industries, computer programs developed to solve various engineering tasks, primarily in the design phase but also in the process of exploitation, to evaluate the effects of performed works and optimize work operations, are increasingly present. In the drive development in mines with underground exploitation, the method of construction of underground roadways that is still mostly used is by drill and blast works, because of several advantages over the methods of mechanized underground construction and unconventional methods of construction. These benefits are reflected primarily in the relatively low cost of obtaining good desired results by drill and blast works. Rock mass excavation is achieved by the destructive effect of explosives, ie the chemical decomposition of explosive material, which is accompanied by a large amount of gases and high pressure acting on the walls of blastholes so that high stresses occur at a certain volume of the working environment (Antunović Kobliška, 1973; Jovanović, 1990). Blasting effects can be classified into two categories, useful work and useless work. Useful work is the grinding and crushing of rock mass as well as the displacement or rejection of destroyed material due to gases. Useless work is the

\footnotetext{
${ }^{1}$ University of Belgrade - Faculty of Mining and Geology, Đušina 7, 11000 Belgrade, Serbia

E-mails: luka.crnogorac@rgf.bg.ac.rs; rade.tokalic@ @rgf.bg.ac.rs;

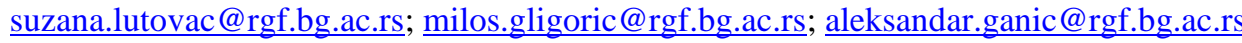


seismic effect of the explosion, the air shock waves and the scattering of pieces of rock mass (Trajković et al, 2005).

Designing of drill and blast works in the construction of underground roadways consists of the adoption of: appropriate shape and dimensions of the cross-section of the underground premises, dimensions (diameter and length) and the total number of blast holes required, the type of blast holes (refractory, auxiliary, peripheral), the appropriate type of explosives and initiation tools to be used, blasting schemes, etc. Many of these steps are time consuming, and the application of various software makes it easier for engineers to design.

Software used in mining can be classified by purpose into three groups: general-purpose software, specialized software and specific-purpose software (Milanović et al. 2019). As the topic is related to the design of underground roadways, the paper will describe in more detail the software JKSimBlast (module 2DFace), which facilitates the graphic design of the adopted shape and dimensions of the cross section of the underground premises and the definition of parameters of drill and blast operations. The software also provides the ability to simulate blasting with the accompanying representation of energy distribution and the impact of blasting on the contours of an underground facility. This assessment of the impact of blasting on the contours of an underground facility is significant, for the designer of underground facilities, from the standpoint of room stability and the choice (if necessary) of the appropriate type of support, as well as of the choice of right drill and blast scheme so that no additions works will be needed to get the wanted shape and dimensions of a cross-section of roadway. The JKSimBlast program belongs to a specific purpose group, and depending on the module, it is applicable for surface (2DBench) or underground exploitation (2Dring), or underground construction (2Dface).

\section{JKSIMBLAST SOFTWARE}

JKSimblast is software developed by JKTech, part of Julius Kruttschnitt Mineral Research Center, University of Queensland (Soft-Blast, 2019; JKTech, 2019) for blast design, analysis and management. Software has been developed in research projects conducted from 1978 to 1994. Research had pioneered different aspects of blast modelling.

JKSimBlast gives an opportunity to user to draw or import (Soft-Blast, 2019):

- excavation outlines: benches, drives, boundaries, etc.,

- drill or import blast holes, single or patterns,

- load decks of explosives, steamming or any other material,

- insert downhole and surface delays, 
- fully customize parameters, explosive and detonator properties,

- simulate the detonation sequence on screen, including scatter,

- analyse energy, damage, timing, relief, fragmentation, vibration and contour blast hole data,

- print tables and scale plans,

- link external files and documents (reports, spreadsheets, photos, etc.) and comments to the blasts,

- organize and open blast and linked data,

- copy all blast data in full 3D coordinates in tabular text format to other applications,

- edit blast data in external application and paste back into design modules and

- copy results from analyses in comprehensive tabular text format.

Software consist of three modules developed for various purposes - 2DBench, 2DRing and $2 \mathrm{DF}$ ace. As the topic of the paper is related to underground premises, only $2 \mathrm{DF}$ ace module will be detailed analysed in the further work.

\subsection{DFace module}

2DFace has been developed for tunnel, drift or shaft blast design and analysis. One design will be presented for a case from an underground drift in bauxite mine to show all the possibilities of design development in 2DFace module in JKSimBlast software.

Modul itself is optimized for creating tunnel, drift or shaft outlines from templates, draw or imported data, drill charge and relief holes, or importing pre-defined cut templates, drill of multiple holes along sides, floor and roof. It has options for charging and timing, fully customize deck and delay properties and charging by length, mass, uncharged collar or collar spacing. With options to analyse and optimize blast such as detonation simulation. detonation contours, burden relief, energy and damage contours in plane or section etc. (Soft-Blast, 2019).

\section{MODEL DESIGN}

Drive "TIP 5" goes through bauxite ore. Based on characteristics of the rock mass, necessary calculations have been done for defining the parameters of drilling and blasting works (FMG, 2012) and are presented in table 1. 
Table 1 Characteristics of rock mass and calculated values of drill and blast parameters

\begin{tabular}{lc}
\hline Unit weight, $\left(t / \mathrm{m}^{3}\right)$ & $\gamma=2.54$ \\
Uniaxial compressive strength, $(\mathrm{MPa})$ & $R_{p}=20$ \\
Protodyakonov coefficient & $f=2.0$ \\
Shape of drifts cross section & Square \\
Area of cross section, $\left(\mathrm{m}^{2}\right)$ & 12.25 \\
Blast holes length, $(\mathrm{m})$ & 1.5 \\
Loading length in blast holes, $(\mathrm{m})$ & 1.395 \\
Diameter of blast holes, $(\mathrm{mm})$ & 32 \\
Number of cut holes & $4+1$ relief \\
Type of cut & 4 \\
Number of auxiliary holes & 12 \\
Number of couture holes & Central parallel with one relief hole \\
Type of explosive used & 28 \\
Cartridge diameter, $(\mathrm{mm})$ & 310 \\
Length of cartridge, $(\mathrm{mm})$ & 200 \\
Cartridge weight, $(\mathrm{g})$ & Amonex -1 Trayal, 2019) \\
\hline
\end{tabular}

\subsection{Model development}

Model development design starts with positioning and orienting the drive outline (easting, northing and level), choose of shape and dimensions of the drifts outline within the "Make drives outline" option box. Figure 1 shows this option box.

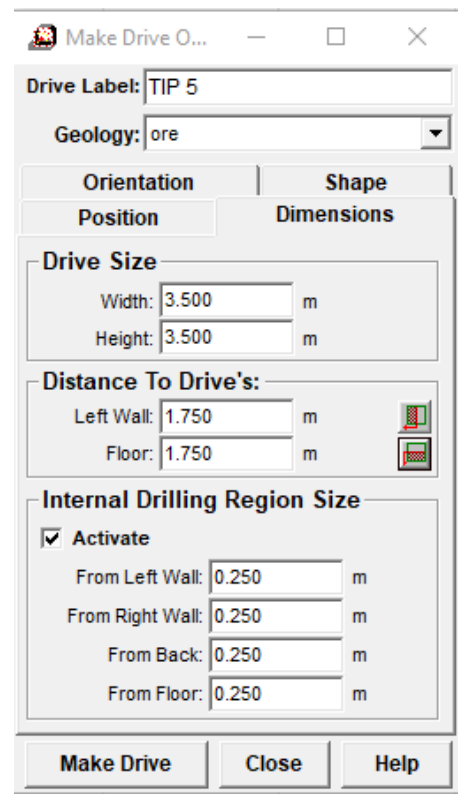

Figure 1 Option box for choice of orientation, shape, position and dimensions of drive 
In the same option box, there is an option for positioning the internal drilling region size, which is selected to be $250 \mathrm{~mm}$ from the drives excavation line. Positioning of drilling section like this is needed so that the hand held borehamer can be used for the drilling of the contour boreholes.

Second step in design process in JKSimBlast 2DFace is choice of parameters of drilling - "hole drilling" option box shown on Figure 2.

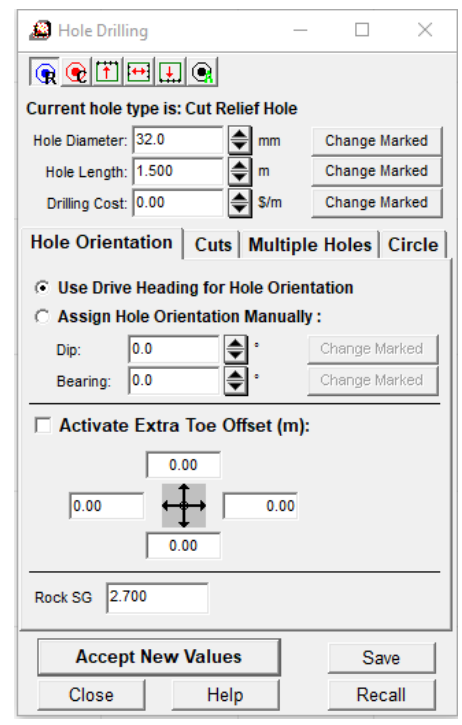

Figure 2 Option box for defining drilling holes parameters

As seen for Figure above, there is number of options for drilling holes, including the hole diameter, hole length, drilling cost (for economic analysis), hole orientation and rock specific gravity value to be assigned for a cut relief hole, cut blast holes, back holes, side holes as well as floor holes and auxiliary/other holes.

On Figure 3 it will be shown the drives outline with, drilling section outline, position of boreholes, alongside the side (west) and up view. 

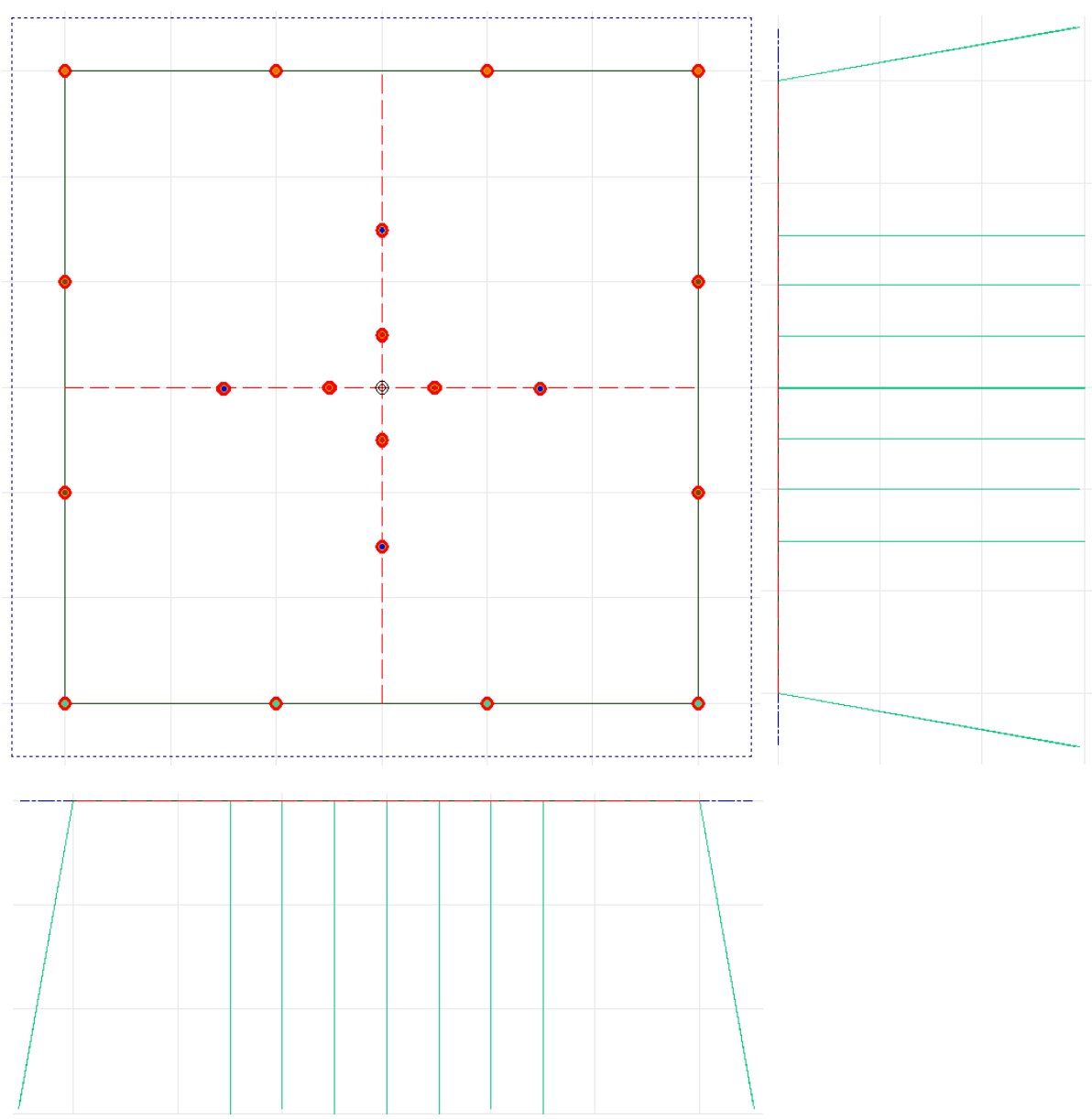

Figure 3 Cross section of a drive with side (west) and up view of boreholes

In case that preview from Figure 3 was done on traditional way in software such as AutoCad, an engineer would need much more time for drawing all the necessary elements of the drawing than in 2DFace.

Next step would be loading of blast holes with appropriate explosive. As shown in Table 1 explosive to be used will be Amonex-1 with characteristic shown in Table 2. 
Table 2 Characteristics of Amonex-1 (Trayal, 2019)

\begin{tabular}{lc}
\hline Property & Value \\
\hline Density $\left(\mathrm{g} / \mathrm{cm}^{3}\right)$ & $1.02-1.10$ \\
Velocity of detonation $(\mathrm{m} / \mathrm{s})$ & 4100 \\
Gas volume $\left(\mathrm{dm}^{3} / \mathrm{kg}\right)$ & 975 \\
Oxygen balance $(\%)$ & +0.13 \\
Heat of explosion $(\mathrm{KJ} / \mathrm{kg})$ & 4103 \\
Temperature of explosion $(\mathrm{K})$ & 2740 \\
Pressure of detonation $($ Kbar $)$ & 45 \\
Initiation & Blasting cap No. 8 \\
\hline
\end{tabular}

Loading of blast holes in 2DFace is done within the "Loading decks" option, shown on Figure 4, where series can be chosen (explosive or steam, or user defined), material (ANFO, emulsion, bulk or cartridge), quantity of explosive (load a length, load a length from a collar, load a percent of borehole, load a mass or load a number of cartridge into the blast hole), and details related to explosive used.

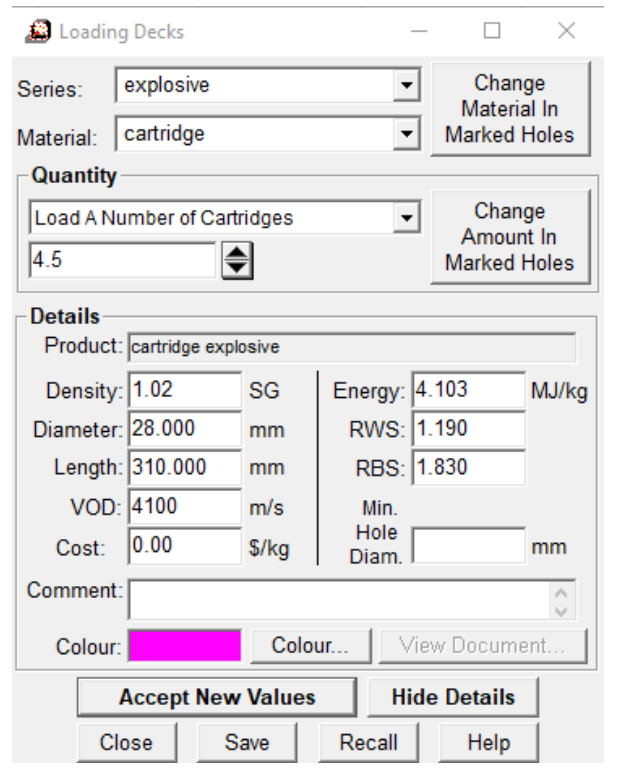

Figure 4 Preview of Loading Decks option box

Next step is to assign downhole delays to each blast hole, from option box "Downhole Delays" a user can chose series (detonator, electric $25 \mathrm{~ms}$, long electric $500 \mathrm{~ms}$, Nonel $25 \mathrm{~ms}$, Surface cord or Surface Nonel or define a series by its own), delays for integrated series can be chosen from dropdown submenu. Initiation cartridge can be placed from collar or from toe of borehole. Distance from face to initiation point can also be assigned manually. In the same option box, parameters of connector or primer (if needed) can be set. Delay, Connector and Primer option sub-boxes also have cost parameter to be 
implemented. For our case, cut blast holes were given series 0 ( $0 \mathrm{~ms}$ delay), 4 auxiliary blast holes series 1 ( $25 \mathrm{~ms}$ delay), 4 side blast holes were assigned series 3 ( 2 on each side with 50ms delay), 4 back (roof) blast holes were assigned series 4 with $75 \mathrm{~ms}$ delay, and 4 floor blast holes were assigned series 5 with a delay of $100 \mathrm{~ms}$.

Final step is to set Surface Delays if they exist from "Surface Delays" option box. In our case, no surface delays were taken and connection for all holes is done with electric connector.

\subsection{Blasting simulation and analysis}

After blasting simulation is done, a software gives several options for analysis. On Figure 5 a preview of time contour is given with the delay contour lines.

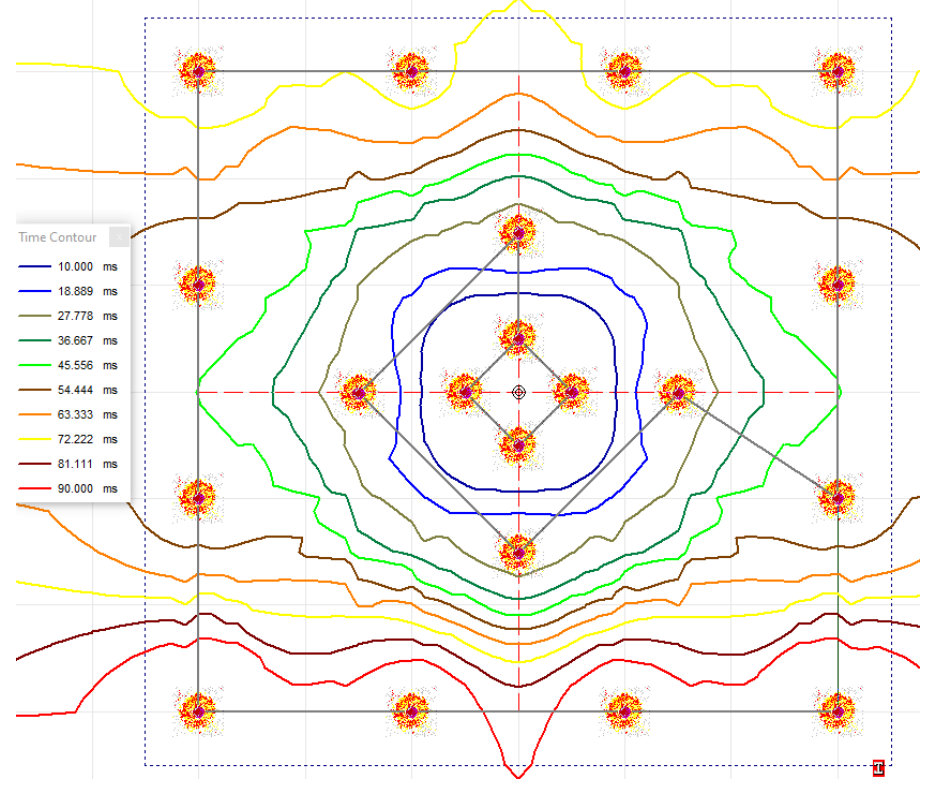

Figure 5 Time contour lines display

Explosive energy distribution is initiated from Tools >Explosive energy distribution menu. After setting input parameters for a calculation (calculation grid resolution $0.01 \mathrm{~m}$ in our case, rock specific gravity, distance along heading (0m our case) and section far distance $(0.5 \mathrm{~m}$ our case) and selection style of analyses (static energy distribution for our case, or dynamic energy distribution) and calculation is done by the software, user gets a preview of energy distribution shown on Figure 6. 


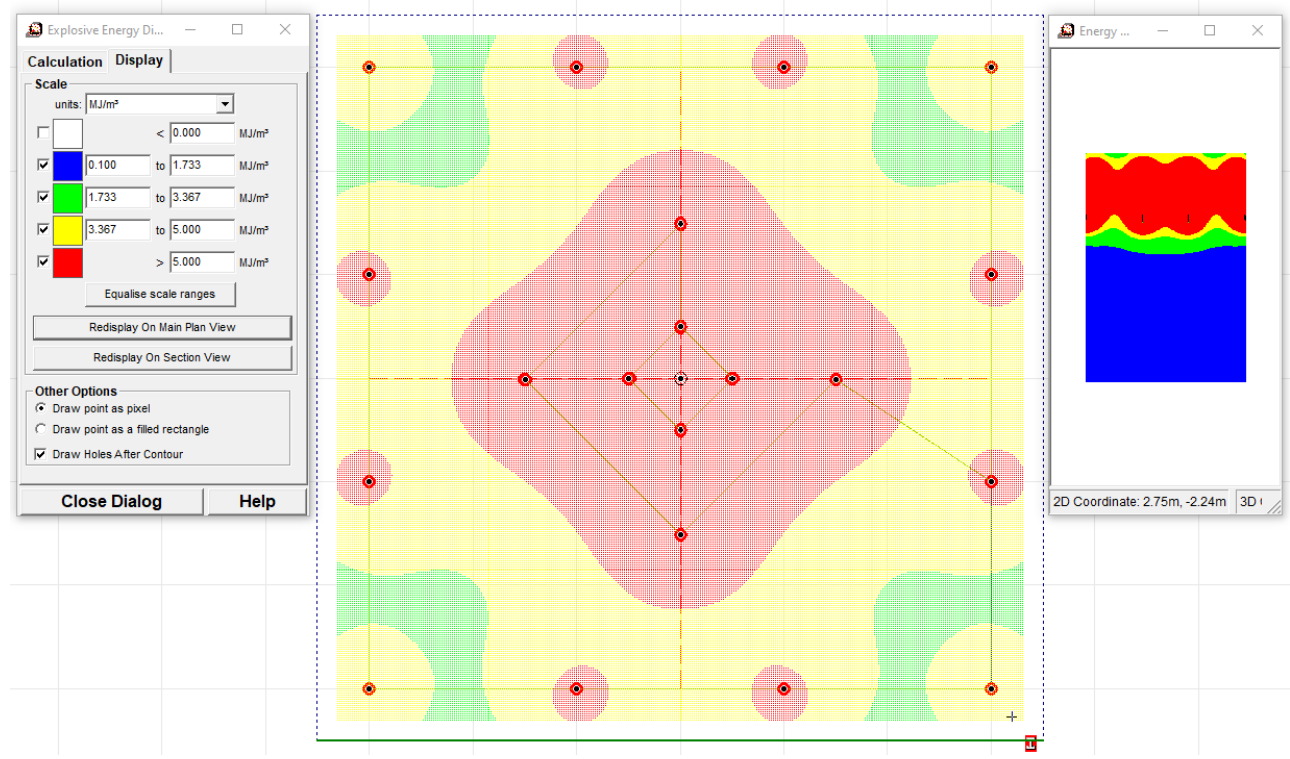

Figure 6 Energy distribution preview in 2DFace software

Display can be done in different units such as $\mathrm{kg} / \mathrm{t}, \mathrm{kg} / \mathrm{m}^{3}, \mathrm{MJ} / \mathrm{t}, \mathrm{MJ} / \mathrm{m}^{3}$ as well as $\mathrm{MJ} / \mathrm{m}^{2}$ (energy flux value), with scales manually assigned if needed. The three-dimensional explosive energy distribution of a charge does not take timing into account and is determined in 2DFace (Soft-Blast, 2006) based on the equation bellow with parameters shown on Figure 7.

$$
P=187,5 \cdot \frac{\rho_{e}}{\rho_{r}} \cdot D^{2} \cdot \frac{1}{h^{2}} \cdot\left(\frac{L_{2}}{r_{2}}-\frac{L_{1}}{L_{2}}\right)
$$

where:

$\rho_{e}$ - explosive density,

$\rho_{r}$ - rock density,

$D$ - diameter of blasthole,

$h, r_{1}$ and $r_{2}$ - distances from point $\mathrm{P}$ to explosive charge as shown on Figure 7 , $L_{1}$ and $L_{2}$ - lengths of the part of explosive charge as shown on Figure 7. 


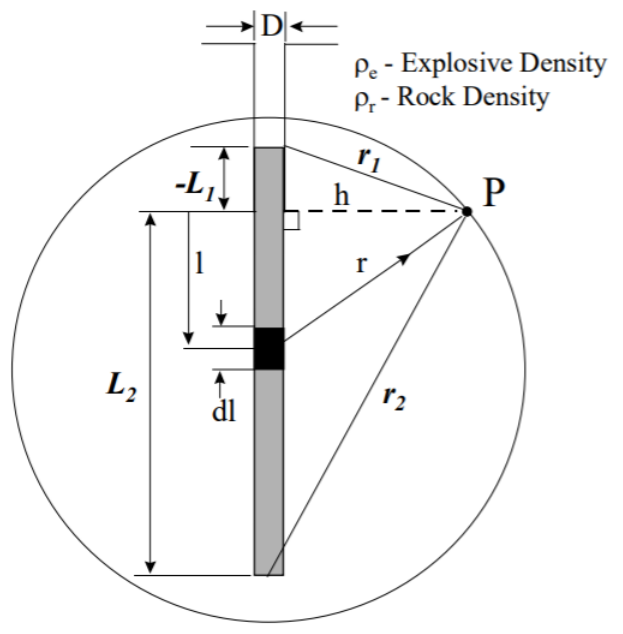

Figure 7 3D Explosive energy concentration at point P (Soft-Blast, 2006)

Within Tools > Holmeberg/Persson PPV contours menu after setting wanted grid resolution $(0.1 \mathrm{~m})$, distance along heading $(0.75 \mathrm{~m})$ and Holmeberg/Persson parameters ( $\mathrm{K}$ and Alpha which are related to rock type and are in situ determined, and for this paper they have not been determined because no field work was yet conducted) user gets a display of PPV distribution as shown on Figure 8.

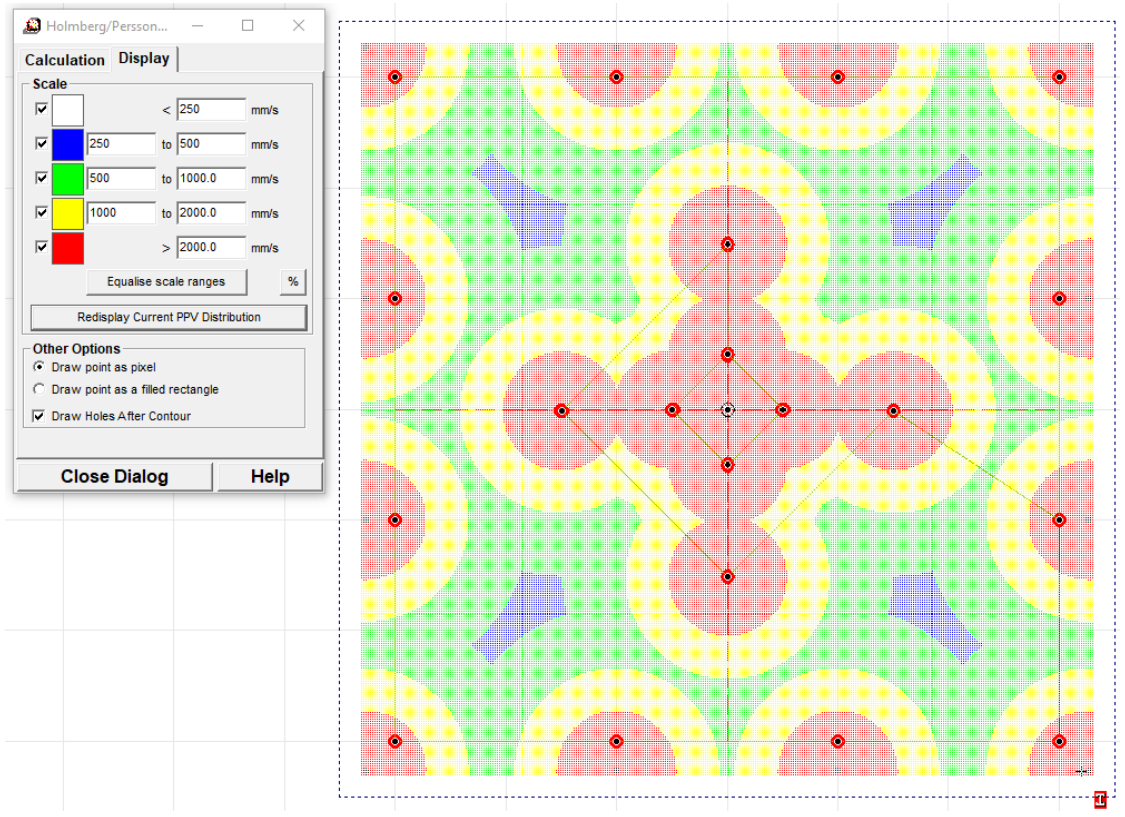

Figure 8 PPV distribution preview in 2DFace software 
A user can use line option to draw a line from centre of blast hole to wanted area of effect (for example red zone) and read the linear value of influence of each blast hole (radius of area of effect).

\section{CONCLUSION}

Some of the features of the JKSimBlast 2DFace are presented in this paper. The application of this software, in addition to providing the necessary input parameters, gives the underground premises designer the ability to:

- draw the outline of the room in a fast and efficient manner,

- easily draw boreholes with the desired geometry and display them in the desired view,

- adopt the desired type of explosive, the length of the explosive charge, the type of initiating system and organize the blast scheme,

- carry out the verification of the blast ignition scheme,

- perform a detonation simulation,

- analyse the energy distribution of explosives,

- perform analysis for single or all blastholes in order to determine the zone of influence of blasting from the point of view of peak particle velocity on the contours of the room,

- easily correct any parameter if the analysis concludes that the adopted borehole layout, type of explosive, borehole geometry may result in off-profile or subprofile excavation.

Thanks to the aforementioned possibilities, after conducting the necessary field tests, it would provide an opportunity for further research work in terms of bringing the energy distribution of explosives to the appearance of off-profile or sub-profile excavation, as well as the peak particle velocity in the contour zone of the underground premises with off-profile or sub-profile excavation. Bringing these influential factors into the relationship would make it easier to choose the right type of support. Comparation of area of projected and area of excavation profile would be needed and best results for analyses of the area of excavation profile would be gathered with use of 3D laser scanners. 


\section{Acknowledgment}

This paper is a part of the Projects TR 33029 under the auspices of the Ministry of Education, Science and Technological Development, Republic of Serbia.

\section{REFERENCES}

MILANOVIĆ, S. et al. (2019) Application of softwares for drilling and blasting. Podzemni radovi, 34 pp. 77-89.

ANTUNOVIĆ KOBLIŠKA, M. (1973) Opšti rudarski radovi. Belgrade: Građevinska knjiga.

JOVANOVIĆ, P. (1990) Izrada jamskih prostorija. Belgrade: University of Belgrade Faculty of Mining and Geology.

SOFT-BLAST (2019) Soft-Blast software in blasting [Online] Available from: http://soft-blast.com/About/Profile [Accessed 21/11/2019].

JKTech (2019) JKTech Pty Ltd. [Online] Available from: http://jktech.com.au/ourcompany [Accessed 21/11/2019].

TRAJKOVIĆ, S. et al. (2005) Tehnika miniranja i potresi. Belgrade: University of Belgrade - Faculty of Mining and Geology.

FMG - FACULTY OF MINING AND GEOLOGY (2012), Glavni rudarski projekat za podzemnu eksploataciju preostalih rezervi boksita u ležištu «Kosturi». Belgrade: University of Belgrade - Faculty of Mining and Geology.

TRAYAL CORPORATION (2019), Trajal Korporacija AD Kruševac, [Online] Available from: https://trayal.rs/en/products/explosives/explosives-and-initiatingdevices/explosives/explosive-cartridges/\#599 [Accessed 06/12/2019].

SOFT-BLAST (2006) JKTech Pty Ltd., User manual [Online] Available from: https://www.soft-blast.com/Support/Downloads/JKSimBlast_A5.pdf [Accessed12/12/2019]. 